\title{
OÚRICUR'
}

\section{INDICADORES DE SUSTENTABILIDADE E GOVERNANÇA PARA $O$ DESENVOLVIMENTO DO PARQUE AQUÍCOLA SUCUPIRA}

\author{
Clauber ROSANOVA ${ }^{\mathbf{1}^{*}}$; Vailton Alves de FARIA $^{\mathbf{1}, 2}$; Flávia Tavares MATOS $^{\mathbf{3}}$
}

\begin{abstract}
${ }^{1}$ Instituto Federal de Educação, Ciência e Tecnologia do Tocantins - IFTO, Campus Palmas. Doutor em Ciências do Ambiente. Endereço: AE 310 Sul, Avenida LO 05, s/n, Plano Diretor Sul, CEP: 77.021-090, Palmas, TO, Brasil. *Autor Correspondente. E-mail: clauber@ifto.edu.br

2Universidade Federal do Tocantins - UFT, Campus Palmas, Doutor em Ciências do Ambiente. Endereço: Av. NS 15, ALCNO, 14, 109 Norte, CP 114, CEP 77001-090, Palmas, TO, Brasil. E-mail: vailton@uft.edu.br ${ }^{3}$ Embrapa Pesca e Aquicultura do Tocantins, Palmas, Tocantins, Brasil. Doutora. Prolongamento da Avenida NS 10, cruzamento com a Avenida LO 18, sentido Norte, s/n - Loteamento Água Fria, CEP 77008-900, Palmas, TO, Brasil.

Recebido: 07.08.2010 Aceito: 30.05.2020

http://doi.org/10.29327/ouricuri.9.2-6
\end{abstract}

Resumo: Atualmente a aquicultura é a atividade de produção de alimentos que mais cresce no mundo. Porém, com críticas constantes da sociedade por seu reconhecido potencial na geração de impactos ambientais, sociais e econômicos, negativos. Diversas são as definições para o termo sustentável e vários são os métodos elaborados e usados para avaliar a sustentabilidade. Alguns deles foram desenvolvidos exclusivamente para a aquicultura, enquanto, outros são aplicações de métodos gerais em sistemas aquícolas. O caminho em direção à sustentabilidade permeia as formas de governança das cadeias produtivas e é incerto, necessitando ser avaliado. Desta forma, o presente estudo propôs um conjunto de indicadores de sustentabilidade e governança para o desenvolvimento da piscicultura em tanques rede no Parque Aquícola Sucupira (Palmas/TO), visando subsidiar ações e políticas públicas para o desenvolvimento do setor. Foram elaborados indicadores de sustentabilidade qualitativos que através de subíndices sociais, econômicos e ambientais geraram um Índice de Sustentabilidade (ISUS) do empreendimento, já para análise de governança foi utilizado o método indutivo com entrevistas aos principais agentes desta cadeia produtiva. Os dados obtidos permitiram concluir que o ISUS do Parque Aquícola Sucupira foi classificado como pouco sustentável $(0,37)$, principalmente nas dimensões econômicas e sociais. A falta de estruturas de governança foi marcante e perceptível em todos os segmentos analisados, o que retrata o real estágio de desorganização e ineficiência da cadeia produtiva da piscicultura no Parque Aquícola Sucupira e no estado como um todo.

Palavras-chave: Ambiente; Produção; Políticas Públicas; Tanque Rede.

\section{SUSTAINABILITY AND GOVERNANCE INDICATORS FOR THE DEVELOPMENT OF SUCUPIRA AQUACOLA PARK} Abstract: Aquaculture is currently the fastest growing food production activity worldwide, but with
constant criticism from the society considering its negative impacts (environmental, social and
economic). There are several definitions for the term "sustainable" and some of them are the
methods developed and used to assess sustainability, which have been developed exclusively for
aquaculture, while others are general method applications in aquaculture systems. The ways to
reach sustainability considers the governance of supply chains, however, is still uncertain and
needs to be evaluated. Thus, the present study proposed a set of sustainability and governance
indicators for the development of fish farming in net cages located in Sucupira Aquaculture Park

Revista Ouricuri, Juazeiro, Bahia, v.9, n.2. p.062-081. jul./dez., 2019.

http://www.revistas.uneb.br/index.php/ouricuri | ISSN 2317-0131 
(Palmas / TO), aiming at support public policies for the development of the sector. Qualitative sustainability indicators were created, through social, economic and environmental sub-indexes, generating a Sustainability Index (ISUS) of the enterprise. For governance analysis, the inductive method was used through interviews with the main agents of this production chain. The results showed that the ISUS of Sucupira Aquaculture Park was classified as unsustainable (0.37), mainly in the economic and social dimensions. The lack of governance structures was remarkable and noticeable in all segments analyzed, which shows the disorganization and inefficiency of the fish production chain in the Sucupira Aquaculture Park and in the state as a whole.

Keywords: Environment; Production; Public Policy; Tank Network.

\section{INDICADORES DE SUSTENTABILIDAD Y GOBERNANZA PARA EL DESAROLLO DEL PARQUE ACUICOLA SUCUPIRA}

Resumen: Actualmente, la acuicultura es la actividad de producción de alimentos de más rápido crecimiento en el mundo. Porém, con críticas constantes de la sociedad por su reconocido potencial para generar impactos ambientales, sociales y económicos negativos. Existen varias definiciones para el término sostenible y varios son los métodos desarrollados y utilizados para evaluar la sustentabilidad, algunos de ellos desarrollados exclusivamente para la acuicultura, mientras que otros son aplicaciones de métodos generales en los sistemas de acuicultura. El camino hacia la sustentabilidad impregna las formas de gobernanza de las cadenas de producción y es incierto, por lo que debe evaluarse. De esta manera, el presente estudio propuso un conjunto de indicadores de sostenibilidad y gobernanza para el desarrollo de la piscicultura en tanques de red en el Parque Aquícola Sucupira (Palmas / TO), con el objetivo de subsidiar acciones y políticas públicas para el desarrollo del sector. Se desarrollaron indicadores cualitativos de sostenibilidad que, a través de subíndices sociales, económicos y ambientales, generaron un Índice de Sostenibilidad (ISUS) para la empresa, mientras que para el análisis de gobernanza se utilizó el método inductivo con entrevistas con los principales agentes de esta cadena de producción. Los datos obtenidos permitieron concluir que el ISUS del Parque Aquícola Sucupira fue clasificado como no sostenible (0.37), principalmente en las dimensiones económica y social. La falta de estructuras de gobernanza fue sorprendente y notable en todos los segmentos analizados, lo que retrata la etapa real de desorganización e ineficiencia en la cadena de producción de piscicultura en el Parque Aquícola Sucupira y en el estado en general.

Palabras clave: Medio Ambiente; Producción; Políticas Públicas; Jaulas Flotantes.

\section{INTRODUÇÃO}

Diante do crescimento mundial da aquicultura, o Brasil vem efetivando o seu potencial frente ao desenvolvimento da atividade, entretanto, se não houve políticas públicas de incentivo e regras bem definidas para o controle e monitoramento, a intensificação do uso dos espaços aquáticos poderá aumentar também os riscos e a severidade de impactos negativos ao ambiente, neutralizando ainda os potenciais benefícios econômicos e sociais da atividade (Seide, 2011).

O desenvolvimento sustentável da aquicultura traz invariavelmente um questionamento: que tipo de sustentabilidade se quer alcançar? A sustentabilidade sociocultural, a sustentabilidade econômica ou a sustentabilidade do meio ambiente natural?

De acordo com Tiago (2011), o capital natural e ecossistêmico é um bem difuso e coletivo, assim, somos levados a considerar que o capital a ser enfocado e melhor valorado seja o capital

Revista Ouricuri, Juazeiro, Bahia, v.9, n.2. p.062-081. jul./dez., 2019.

http://www.revistas.uneb.br/index.php/ouricuri | ISSN 2317-0131 
natural e ecossistêmico e que os capitais socioculturais e econômicos devam ser direcionados e onerados com vista ao melhor alcance dos objetivos e metas que mantenham e/ou aumentem aquele capital.

Valenti (2008) definiu aquicultura sustentável como uma produção lucrativa de organismos aquáticos que mantém uma interação harmônica duradoura com os ecossistemas e as comunidades humanas. Dentre as formas de mensuração da sustentabilidade, o uso de conjuntos de indicadores assume papel de destaque, sendo útil para o planejamento, implementação e monitoramento de políticas e para a tomada de decisões nas esferas pública e privada (Carvalho e Barcellos, 2009).

Tiago (2002; 2007) pondera que, para uma melhor reflexão sobre a atividade aquícola, seria interessante o estabelecimento de um fórum multi e interdisciplinar, específico e permanente, para discussão da sustentabilidade aquícola adequada a cada tipo de situação possível.

A governança ambiental é, no conceito de Cavalcanti (2004), o arcabouço institucional de regras, instituições, processos e comportamentos que afetam a maneira como os poderes são exercidos na esfera de políticas ou ações ligadas às relações da sociedade com o sistema ecológico. Tratada como algo associado à capacidade de o Estado formular e implementar políticas públicas efetivas, atua fortemente nos temas ambientais, resultando em modelos de articulação institucional que propiciam a gestão ambiental do desenvolvimento (Câmara, 2013).

Segundo Tiago e Cipolli (2010), é necessário pensar e construir uma governança da aquicultura que produza interferências positivas nos arranjos produtivos locais (APLs) e globais das organizações que produzam resultados favoráveis à gestão responsável dos recursos naturais essenciais ao alcance do bem-estar comum.

A falta do exercício da governança local é muito marcante nos parques aquícolas e segundo Suzigan et al. (2007), governança em arranjos produtivos locais diz respeito aos diferentes modos de coordenação, intervenção e participação nos processos de decisão locais, dos diferentes agentes (empresas, instituições, ou mesmo um agente coordenador).

De acordo com Humprey e Schmitz (2000), se a governança for efetuada pelo poder público, então haverá criação e a manutenção de organismos voltados à promoção do desenvolvimento dos produtores locais e agências governamentais de desenvolvimento. Caso a governança seja coordenada por agentes privados, então essas instituições deverão atuar por meio de ações de fomento à competitividade e de promoções do conjunto das empresas.

Desta forma, o presente estudo propôs um conjunto de indicadores de sustentabilidade e governança para o desenvolvimento do Parque Aquícola Sucupira, visando subsidiar ações e políticas para seu desenvolvimento. Acredita-se ainda que essa proposta possa servir como um modelo indutor da atividade, contribuindo para mitigação de riscos, promovendo a viabilidade 
econômica do empreendimento e consequentemente a inclusão social e a manutenção da qualidade ambiental.

\section{MATERIAL E MÉTODOS}

O reservatório de Lajeado (Figura 1) localiza-se no estado do Tocantins, entre os municípios de Lajeado, Miracema do Tocantins, Palmas (capital do estado), Porto Nacional, Brejinho de Nazaré e Ipueiras. Neste Reservatório foram demarcados inicialmente 11 Parques Aquícolas, dentre os quais três foram cancelados, um em regularização, dois aguardam serem licitados e apenas cinco tiveram suas áreas licitadas.

Estes cinco Parques (Tabela 1), somam uma capacidade de produção de 22.432 toneladas por ano, no entanto, apenas $85 \%$ corresponde ao que se encontra atualmente cedido para a aquicultura.

O número total de cessionários destes cinco Parques Aquícolas é de 242 (Tabela 1). Deste total, 239 são cessionários de áreas não onerosas, com capacidade de produção por área de 48 toneladas por ano, e apenas três são cessionários de áreas aquícolas onerosas, com capacidade de produção de 2.500 toneladas por ano (MPA, 2015).

Tabela 1. Porcentagem cedida dos Parque Aquícolas de Lajeado - TO e capacidade de produção média por cessionário.

\begin{tabular}{cccccc}
\hline Parques de Lajeado & $\begin{array}{c}\text { Outorga emitida por } \\
\text { Parque }\end{array}$ & $\begin{array}{c}\text { Produção } \\
\text { outorgada } \\
\text { cedida }\end{array}$ & \% cedida & $\begin{array}{c}\text { No de } \\
\text { cessionários }\end{array}$ & $\begin{array}{c}\text { Capacidade de } \\
\text { produção média }\end{array}$ \\
\hline Miracema-Lajeado & 720 & 672 & 93 & 14 & 48 \\
Sucupira & 10.032 & 9.168 & 91 & 191 & 48 \\
Santa Luzia & 10.000 & 7.500 & 75 & 3 & 2.500 \\
Brejinho 01 & 624 & 624 & 100 & 13 & 48 \\
Brejinho 02 & 1.056 & 1.008 & 95 & 21 & 48 \\
Total Geral & 22.432 & 18.972 & $85 \%$ & 242 & 78 \\
\hline
\end{tabular}

Fonte: MPA 2015, adaptado pelo autor.

O lago da usina hidrelétrica Luís Eduardo Magalhães (também chamado Lago de Palmas) tem uma extensão de $170 \mathrm{~km}$, com latitude de 1012'46" ao Sul e longitude de 4821'37" a Oeste, com altitude de 230 metros sobre o nível do mar.

O Parque Aquícola Sucupira foi demarcado no ano de 2013 para produzir 10.036 toneladas de peixes por ano. Estão cedidas 191 áreas não onerosas que somam uma capacidade de produção de 9.168 toneladas de peixes por ano. Cada área não onerosa tem capacidade de produzir 48 toneladas por ano. Atualmente, constam 18 cessionários produzindo no Parque Aquícola Sucupira, sendo todos associados a Associação Bom Peixe. Assim, se multiplicado pela sua produção individual, esses cessionários somam uma capacidade de produção de 1.344 
toneladas de peixe por ano e o potencial de produção somente destes 18 cessionários equivale a $15 \%$ da produção da aquicultura de todo o estado do Tocantins (MPA, 2015).

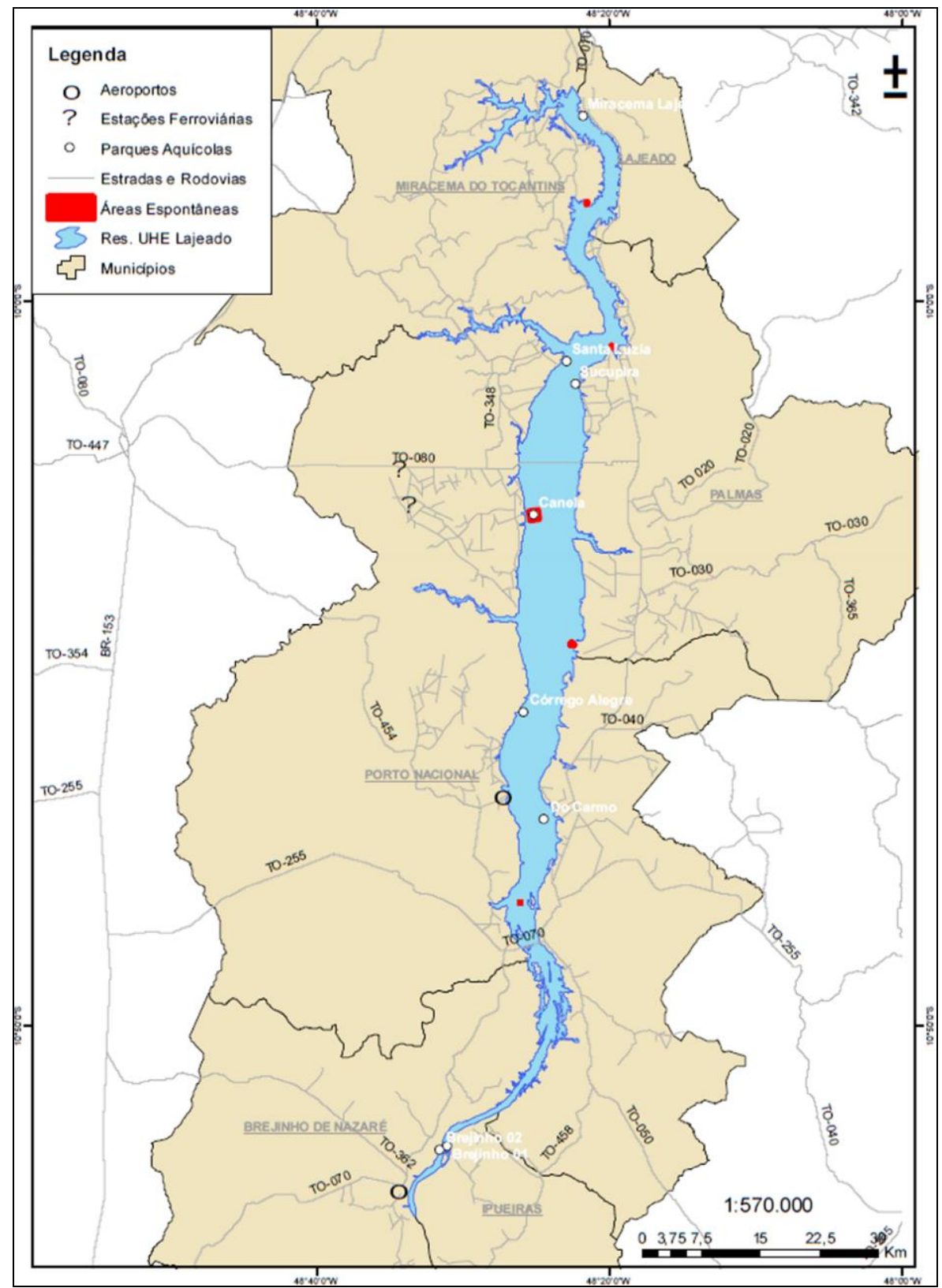

Figura 1. Reservatório do Lajeado com indicação das Áreas e Parques Aquícolas. Fonte: MPA 2015.

A definição de indicadores de sustentabilidade específicos para parques aquícolas continentais foi baseada nos trabalhos de Boyd et al. (2007), Valenti (2008), Valenti et al. (2011) e Silva et al. (2012), bem como na legislação aquícola brasileira (Brasil, 1997), e são apresentados de forma resumida na tabela 1 . No caso do presente estudo analisaremos apenas a fase de operação, uma vez que o parque já está implantado (Tabela 2). Na tabela 3 é apresentado as atividades, impactos positivos e ações de controle na fase de operação do parque aquícola. 
Tabela 2. Atividades, impactos negativos e ações propostas para a fase de instalação de parques aquícolas.

\begin{tabular}{|c|c|c|}
\hline Atividade & Impacto associado & Ações de mitigação ou controle \\
\hline \multirow{3}{*}{$\begin{array}{l}\text { Geração de } \\
\text { resíduos } \\
\text { sólidos: } \\
\text { Embalagem } \\
\text { Equipamento } \\
\text { Peixe }\end{array}$} & $\begin{array}{lr}\text { Destinação inapropriada; } \\
\text { Contaminação } & \text { do } \\
\text { solo/água; Transmissão de }\end{array}$ & $\begin{array}{l}\text { Acompanhamento técnico e disponibilização de coletores } \\
\text { de resíduo orgânico e reciclável para o } \\
\text { acondicionamento conforme normas de coleta de lixo do } \\
\text { Município. }\end{array}$ \\
\hline & doenças. & $\begin{array}{l}\text { Implantação de procedimento para o controle } \\
\text { operacional da destinação dos resíduos }\end{array}$ \\
\hline & Esgotamento dos aterros & $\begin{array}{l}\text { Instrução e capacitação dos aquicultores: para a redução } \\
\text { na produção de resíduos sólidos }\end{array}$ \\
\hline \multirow{4}{*}{$\begin{array}{l}\text { Emissão de } \\
\text { efluentes e } \\
\text { resíduos do } \\
\text { cultivo - } \\
\text { ração, fezes e } \\
\text { metabólitos }\end{array}$} & $\begin{array}{l}\text { Disponibilização no corpo } \\
\text { hídrico de carga de }\end{array}$ & $\begin{array}{l}\text { Assistência e capacitação dos produtores para o uso de } \\
\text { ração adequada e Boas Práticas de Manejo }\end{array}$ \\
\hline & $\begin{array}{lcr}\text { nutrientes } & \text { e } & \text { matéria } \\
\text { orgânica; } & \text { Afloração } & \text { de } \\
\text { algas; } & \text { Depleção } & \text { do } \\
\text { oxigênio; } & & \end{array}$ & $\begin{array}{l}\text { Monitoramento da qualidade da água e } \\
\text { Sedimento }\end{array}$ \\
\hline & $\begin{array}{l}\text { Alteração na qualidade da } \\
\text { água. }\end{array}$ & Controle de qualidade da produção \\
\hline & $\begin{array}{l}\text { Alteração na estrutura } \\
\text { trófica da ictiofauna local }\end{array}$ & Monitoramento da ictiofauna \\
\hline $\begin{array}{l}\text { Fuga de } \\
\text { espécimes }\end{array}$ & $\begin{array}{l}\text { Alteração na estrutura } \\
\text { trófica do corpo hídrico; } \\
\text { Transmissão de doenças } \\
\text { para a fauna aquática. }\end{array}$ & $\begin{array}{l}\text { Assistência técnica para orientar a utilização de tanques } \\
\text { com sistema de fechamento e a organização dos } \\
\text { produtores para fiscalização dos cultivos. } \\
\text { Capacitação quanto as Boas Práticas de Manejo }\end{array}$ \\
\hline \multirow{2}{*}{$\begin{array}{l}\text { Operação de } \\
\text { parques } \\
\text { aquícolas }\end{array}$} & $\begin{array}{l}\text { Conflito de uso da água } \\
\text { entre fazendeiros, turistas, } \\
\text { embarcações, } \\
\text { concessionária e } \\
\text { aquicultores. }\end{array}$ & $\begin{array}{l}\text { Assistência técnica e capacitação dos produtores para } \\
\text { operação adequada do parque aquícola } \\
\text { Monitoramento da qualidade da água }\end{array}$ \\
\hline & $\begin{array}{l}\text { Alteração paisagística; } \\
\text { Poluição visual. }\end{array}$ & $\begin{array}{l}\text { Acompanhamento técnico e capacitação para o } \\
\text { ordenamento dos tanques e da sinalização náutica. }\end{array}$ \\
\hline
\end{tabular}

Fonte: Seide (2011), adaptado de pelo autor.

A metodologia proposta por Brabo et al. (2015) para avaliação da sustentabilidade de parques aquícolas continentais considerou as dimensões ambiental, econômica e social. Cada dimensão contou com um conjunto de indicadores representado por um subíndice, denominados de Subíndice Ambiental (SA), Subíndice Econômico (SE) e Subíndice Social (SS). Posteriormente, estes indicadores foram validados e mensurados por meio de observações in loco e entrevistas com técnicos especializados de órgãos públicos ambientais (três entrevistados), de fomento (três 
entrevistados), assistência técnica e extensão rural (três entrevistados) e produtores (18 entrevistados), no período de agosto de 2017 a julho de 2018.

Tabela 3. Atividades, impactos positivos e ações propostas para a fase de operação de parques aquícolas.

\begin{tabular}{|c|c|c|}
\hline Atividade & Impacto Associado & Ações de Maximização \\
\hline \multirow{3}{*}{$\begin{array}{l}\text { Produção de pescado em } \\
\text { tanques-rede (social) }\end{array}$} & $\begin{array}{l}\text { Melhoria da renda e qualidade de } \\
\text { vida. }\end{array}$ & $\begin{array}{l}\text { Assistência técnica e capacitação } \\
\text { para controle da qualidade do }\end{array}$ \\
\hline & $\begin{array}{l}\text { Geração de divisas pela } \\
\text { arrecadação de tributos. }\end{array}$ & $\begin{array}{l}\text { pescado e aplicação das Boas } \\
\text { Práticas de Manejo. }\end{array}$ \\
\hline & $\begin{array}{l}\text { Aumento da oferta e o consumo de } \\
\text { pescado. }\end{array}$ & $\begin{array}{l}\text { Assistência e capacitação dos } \\
\text { produtores nas áreas de } \\
\text { empreendedorismo e gestão. }\end{array}$ \\
\hline \multirow[b]{2}{*}{$\begin{array}{l}\text { Produção de pescado em } \\
\text { tanques-rede (ambiental) }\end{array}$} & $\begin{array}{l}\text { Diminuição da pressão pesqueira } \\
\text { sobre a ictiofauna. }\end{array}$ & $\begin{array}{l}\text { Assistência técnica e capacitação } \\
\text { para aplicação das Boas Práticas } \\
\text { de Manejo. }\end{array}$ \\
\hline & $\begin{array}{l}\text { Geração de dados sobre o meio } \\
\text { ambiente local. } \\
\text { Pressão para melhorar o controle } \\
\text { das fontes de poluição. }\end{array}$ & $\begin{array}{l}\text { Divulgação dos resultados da } \\
\text { produção e do monitoramento } \\
\text { ambiental. }\end{array}$ \\
\hline \multirow{2}{*}{$\begin{array}{l}\text { Utilização da sinalização } \\
\text { náutica nas áreas de cultivo }\end{array}$} & Redução dos conflitos & $\begin{array}{l}\text { Assistência e capacitação para a } \\
\text { escolha dos materiais e instalação } \\
\text { de sinalização náutica harmônica e } \\
\text { conforme as exigências legais. }\end{array}$ \\
\hline & $\begin{array}{l}\text { Diminuição dos riscos de acidente } \\
\text { com embarcações }\end{array}$ & $\begin{array}{l}\text { Divulgação das atividades } \\
\text { desenvolvidas no parque, para a } \\
\text { comunidade local. }\end{array}$ \\
\hline
\end{tabular}

Fonte: Seide (2011), adaptado de pelo autor.

Os indicadores de sustentabilidade propostos foram exclusivamente qualitativos, visto que indicadores quantitativos aumentam consideravelmente a subjetividade da análise (Silva et al., 2012). Os valores dos subíndices foram gerados a partir da média aritmética das pontuações de zero (0) e um (1) estabelecidas para os indicadores da dimensão, de forma que o valor zero (0) significou uma condição desfavorável à sustentabilidade e o um (1), uma condição favorável (Brabo, 2015). Em seguida, a média aritmética dos valores obtidos para os três subíndices formou o Índice de Sustentabilidade (ISUS), avaliado pela seguinte escala de desempenho, adaptada de Valenti (2008): insustentável $(00,25)$; pouco sustentável $(0,26-0,50)$; potencialmente sustentável (0,51-0,75); e sustentável $(0,76-1,0)$.

O método de pesquisa utilizado para se estudar a governança no parque Aquícola Sucupira foi o método indutivo. O qual infere-se uma verdade geral ou universal não contida nas partes examinadas, partindo de dados particulares suficientemente constatados. Portanto, 0 
objetivo dos argumentos indutivos é levar a conclusões cujo conteúdo é muito mais amplo do que o das premissas nas quais se basearam (Lakatos e Marconi, 1986).

Para o levantamento de dados e de informações relevantes à investigação e à compreensão das questões propostas, foram utilizadas técnicas de documentação direta e indireta, e observação direta intensiva. A documentação indireta foi calcada em pesquisa documental e pesquisa bibliográfica. A fonte de coleta de dados da pesquisa documental limitouse aos documentos, escritos ou não, denominados de fontes primárias. Por outro lado, a pesquisa bibliográfica ou de fontes secundárias, abrangeu toda bibliografia já publicada tanto na comunicação escrita quanto na oral. Este estudo fez uso de ambas as fontes, primária e secundária.

Neste estudo foi utilizada, também, a entrevista semiestruturada que, segundo Lakatos e Marconi (1986), oferece todas as perspectivas possíveis para que o entrevistado alcance a liberdade e a espontaneidade necessárias, enriquecendo a pesquisa. As entrevistas foram delineadas com base em questões apoiadas em teorias e hipóteses que interessam a pesquisa. As entrevistas foram realizadas, com agentes potenciais diretamente envolvidos na dinâmica local do sistema produtivo, essa delimitação deve-se, ao fato desses agentes, geralmente, possuírem uma visão sistêmica da dinâmica da produção local e regional.

No total foram realizadas 20 entrevistas e os agentes entrevistados foram os seguintes: presidente da Associação Bom Peixe, um consultor da FAO especialista em aquicultura em águas da união, dois pesquisadores da EMBRAPA e dois pesquisadores do IFTO que desenvolvem trabalhos no parque, dois extensionistas rurais da SEDER e dois do Ruraltins, o coordenador da pasta de agronegócios do SEBRAE/TO (Agência de Apoio ao Empreendedor e Pequeno Empresário) e a diretora de produção animal da SEAGRO. Em seguida foram entrevistados um produtor de alevinos, dois cessionários não onerosos e um oneroso do parque, um representante comercial de insumos (ração), um gerente de empresa frigorífica e dois gerentes de agência de fomento e crédito financeiro.

\section{RESULTADOS E DISCUSSÃO}

Todos os resultados foram analisados e discutidos de acordo com os indicadores de sustentabilidade nas dimensões ambiental, econômica e social, de acordo com as respostas dos 27 participantes da pesquisa (Tabela 4). Para cada indicador de sustentabilidade, foram calculados seus respectivos subíndices.

No Parque Aquícola Sucupira constatou-se a produção de duas espécies principais de peixes, o tambaqui (Colossoma macroponum) e o pirarucu (Arapaima gigas), peixes autóctones da Bacia Hidrográfica Araguaia - Tocantins, de acordo com a classificação da Portaria IBAMA n 145 de 29 de outubro de 1998 (Brasil, 1998). 
Tabela 4. Indicadores de sustentabilidade nas dimensões ambiental, econômica e social para parques aquícolas continentais com seus respectivos critérios de mensuração.

\begin{tabular}{|c|c|c|}
\hline Dimensão & Indicador & Critério de Mensuração \\
\hline & $\begin{array}{l}\text { Espécie(s) utilizada(s) no } \\
\text { empreendimento }\end{array}$ & $\begin{array}{l}\text { Exótica(s), alóctone(s) ou híbrida(s) (0) / Apenas autóctone(s) } \\
\text { ou com população comprovadamente estabelecida na bacia } \\
\text { hidrográfica }\end{array}$ \\
\hline & Capacidade suporte do corpo & $\begin{array}{l}\text { Volume útil de tanques-rede instalados acima da capacidade } \\
\text { suporte estimada pela Agência de Águas (ANA) (0) / }\end{array}$ \\
\hline & hídrico & $\begin{array}{l}\text { Volume útil de tanques-rede instalados igual ou abaixo da } \\
\text { capacidade suporte estimada pela Agência Nacional de Águas } \\
\text { (ANA) (1) }\end{array}$ \\
\hline & $\begin{array}{l}\text { Monitoramento sistemático } \\
\text { de variáveis físicas, químicas } \\
\text { e biológicas de qualidade da } \\
\text { água do corpo hídrico (com } \\
\text { frequência no mínimo } \\
\text { trimestral) }\end{array}$ & Não existe (0) / Existe (1) \\
\hline \multirow[t]{8}{*}{ Ambiental } & $\begin{array}{l}\text { Material da tela de contenção } \\
\text { dos tanques-rede utilizadas } \\
\text { no empreendimento }\end{array}$ & $\begin{array}{l}\text { Estruturas de plástico ou material similar (0) / Apenas } \\
\text { estruturas de arame galvanizado revestido de PVC ou material } \\
\text { similar (1) }\end{array}$ \\
\hline & Profilaxia das formas jovens & Não existe ou eventual (0) / \\
\hline & $\begin{array}{l}\text { utilizadas no } \\
\text { empreendimento }\end{array}$ & Realizada por todos os usuários (1) \\
\hline & $\begin{array}{l}\text { Uso de produtos químicos } \\
\text { e/ou antibióticos no } \\
\text { tratamento de enfermidades } \\
\text { dos peixes, exceto sal } \\
(\mathrm{NaCL})\end{array}$ & Existe (0) / Não existe (1) \\
\hline & $\begin{array}{l}\text { Impacto visual } \\
\text { empreendimento }\end{array}$ & $\begin{array}{l}\text { Negativo (estruturas improvisadas e/ou sem padronização) } \\
(0) /\end{array}$ \\
\hline & & $\begin{array}{l}\text { Positivo (apenas estruturas específicas para a atividade e } \\
\text { padronizadas) (1) }\end{array}$ \\
\hline & $\begin{array}{l}\text { Estudo de mercado para a(s) } \\
\text { espécie(s) utilizadas no } \\
\text { empreendimento }\end{array}$ & Não realizado (0) / Realizado (1) \\
\hline & nto & $\begin{array}{l}\text { Insatisfatória (usuários não controlam o custo de produção, o } \\
\text { consumo de ração e/ou não realizam biometrias periódicas) } \\
\text { (0) / }\end{array}$ \\
\hline \multirow[t]{3}{*}{ Econômica } & & $\begin{array}{l}\text { Satisfatória (todos os usuários controlam o custo de produção, } \\
\text { o consumo de ração e realizam biometrias periódicas) (1) }\end{array}$ \\
\hline & $\begin{array}{l}\text { Disponibilidade local de } \\
\text { insumos básicos (ração e } \\
\text { formas jovens) }\end{array}$ & Não existe (0) / Existe (1) \\
\hline & $\begin{array}{l}\text { Assistência técnica aos } \\
\text { usuários }\end{array}$ & Não existe ou eventual (0) / Existe (1) \\
\hline
\end{tabular}

Fonte: Brabo et al. (2015), adaptado pelo autor. 
Tabela 4. Continuação

\begin{tabular}{|c|c|c|}
\hline Dimensão & Indicador & Critério de Mensuração \\
\hline \multirow{3}{*}{ Econômica } & $\begin{array}{l}\text { Possibilidades de utilização } \\
\text { de crédito rural na atividade }\end{array}$ & Não existe (0) / Existe (1) \\
\hline & $\begin{array}{l}\text { Logística e infraestrutura do } \\
\text { empreendimento }\end{array}$ & $\begin{array}{l}\text { Insatisfatória (não há acesso por via terrestre por via terrestre } \\
\text { ao empreendimento e/ou não existe estrutura para } \\
\text { armazenamento de ração e equipamentos) }(0) \text { / Satisfatória } \\
\text { (há acesso por via terrestre ao empreendimento e existe } \\
\text { estrutura para armazenamento de ração e equipamentos) (1) }\end{array}$ \\
\hline & $\begin{array}{l}\text { Possibilidade de beneficiar } \\
\text { o produto localmente }\end{array}$ & $\begin{array}{l}\text { Não existe estrutura para beneficiamento de pescado }(0) \text { / } \\
\text { Existe estrutura para beneficiamento de pescado (1) }\end{array}$ \\
\hline \multirow{7}{*}{ Social } & $\begin{array}{l}\text { Conflito pelo uso da água } \\
\text { na área do empreendimento }\end{array}$ & Existe (0) / Não existe (1) \\
\hline & $\begin{array}{l}\text { Capacitação dos usuários } \\
\text { para atuar na atividade }\end{array}$ & $\begin{array}{l}\text { Insatisfatória (usuários não receberam capacitação) (0) / } \\
\text { Satisfatória (todos os usuários receberam capacitação) (1) }\end{array}$ \\
\hline & $\begin{array}{lr}\text { Atuação } & \text { da(s) } \\
\text { organização(ões) } & \text { social(is) } \\
\text { dos usuários } & \end{array}$ & $\begin{array}{l}\text { Não existe aquisição de insumos e/ou comercialização de } \\
\text { forma coletiva (0) / Existe aquisição de insumos e } \\
\text { comercialização de forma coletiva (1) }\end{array}$ \\
\hline & Consumo local de produção & Não existe ou eventual (0) / Prioridade (1) \\
\hline & $\begin{array}{l}\text { Segurança } \\
\text { empreendimento }\end{array}$ & $\begin{array}{l}\text { Deficiente (existem casos de furto dos peixes e/ou } \\
\text { depredação de estruturas) (0) / Eficiente (não existem casos } \\
\text { de furto de peixes e depredação das estruturas (1) }\end{array}$ \\
\hline & $\begin{array}{l}\text { Adaptação dos usuários à } \\
\text { atividade }\end{array}$ & $\begin{array}{l}\text { Difícil (usuários nunca praticaram psicultura ou outra } \\
\text { atividade zootécnica em sistema intensivo por pelo menos } \\
\text { um ano) (0) / Fácil (todos os usuários já praticaram uma } \\
\text { psicultura e/ou outra atividade zootécnica em sistema } \\
\text { intensivo por pelo menos um ano) (1) }\end{array}$ \\
\hline & $\begin{array}{l}\text { Geração de empregos } \\
\text { diretos no empreendimento, } \\
\text { exceto auto empregos }\end{array}$ & Não existe (0) / Existe (1) \\
\hline
\end{tabular}

Fonte: Brabo et al. (2015), adaptado pelo autor.

O volume útil de tanques rede instalado foi menor do que a capacidade de suporte estimada na implantação do parque e constatou-se ainda que a operadora da hidrelétrica não possui programa de monitoramento de variáveis físicas, químicas e biológicas de qualidade da água do corpo hídrico com frequência bimestral, conforme previsto na Instrução Normativa Interministerial $n^{\circ} 6$ de 31 de maio de 2004 (Brasil, 2004).

Os tanques-rede instalados utilizavam exclusivamente tela de contenção de arame galvanizado revestido de PVC, o que minimiza a possibilidade de rompimento da estrutura e consequente fuga de peixes, porém as estruturas não são padronizadas, há tanques de diversos tamanhos, apontamentos e estruturas de flutuação.

Nenhum dos usuários efetuava quarentena das formas jovens e apenas eventualmente

Revista Ouricuri, Juazeiro, Bahia, v.9, n.2. p.062-081. jul./dez., 2019.

http://www.revistas.uneb.br/index.php/ouricuri | ISSN 2317-0131 
aplicavam banhos preventivos utilizando sal ( $\mathrm{NaCl})$, práticas de manejo profilático que reduzem o risco de disseminação de patógenos sem ocorrência natural no ambiente.

Dias et al. (2012) afirmaram que a eutrofização e a disseminação de espécies de peixes e parasitas sem ocorrência natural nos corpos d'água onde foram demarcados parques aquícolas são os principais riscos de impacto ambiental destes empreendimentos. Dos sete indicadores de sustentabilidade ambiental propostos, cinco fazem referência aos seguintes impactos: capacidade de suporte do corpo hídrico e monitoramento sistemático de qualidade da água estando diretamente relacionados à eutrofização. Enquanto a espécie produzida no empreendimento, o material da tela de contenção dos tanques-rede e a profilaxia das formas jovens correspondem aos impactos relacionados à propagação de peixes e patógenos.

De acordo com a tabela 5 , o subíndice de sustentabilidade ambiental encontrado foi de 0,57 , classificado como potencialmente sustentável $(0,51-0,75)$ pela escala de desempenho, de Valenti (2008).

Tabela 5. Proposta de indicadores de sustentabilidade para formação do Subíndice Ambiental (SA) preenchida com dados referentes ao Parque Aquícola Sucupira.

\begin{tabular}{lc}
\multicolumn{1}{c}{ Indicador de Sustentabilidade } & Pontuação \\
\hline Espécie(s) utilizada(s) no empreendimento & 1 \\
Capacidade suporte do corpo hídrico & 1 \\
Monitoramento sistemático de qualidade da água do corpo hídrico & 0 \\
Material da tela de contenção dos tanques-rede & 1 \\
Profilaxia das formas jovens utilizadas no empreendimento & 1 \\
Uso de produtos químicos elou antibióticos & 0 \\
Impacto visual do empreendimento & 0 \\
Total & 4 \\
Subíndice Ambiental (SA) & 0,57
\end{tabular}

Fonte: Brabo et al. (2015), adaptado pelo autor.

Brabo et al. (2015) utilizando-se da mesma escala relataram subíndice de sustentabilidade ambiental de 0,71, classificado como potencialmente sustentável, para o Parque Aquícola Breu Branco III no reservatório de Tucuruí, estado do Pará. Apesar de estarem enquadrados na mesma escala de sustentabilidade ambiental o Parque Aquícola Breu Branco III tem a vantagem do monitoramento sistemático da qualidade da água.

Para os indicadores de sustentabilidade econômica verificou-se que não houve estudo de mercado para a escolha da espécie a ser produzida no Parque Aquícola Sucupira, o que se reproduziu em dificuldades na comercialização do produto; a gestão do empreendimento era deficiente no que diz respeito ao controle do custo de produção, apesar de alguns usuários 
realizarem biometrias periódicas e ajustes na quantidade de ração fornecida aos peixes (Tabela $6)$.

Tabela 6. Proposta de indicadores de sustentabilidade para formação do Subíndice Econômico (SE) preenchida com dados referentes ao Parque Aquícola Sucupira.

\begin{tabular}{lc}
\hline \multicolumn{1}{c}{ Indicador de Sustentabilidade } & Pontuação \\
\hline Estudo de mercado para a(s) espécie(s) utilizada(s) & 0 \\
Gestão do empreendimento & 0 \\
Disponibilidade local de insumos & 1 \\
Assistência técnica aos usuários & 0 \\
Utilização de crédito rural na atividade & 0 \\
Logística e infraestrutura do empreendimento & 1 \\
Possibilidade de beneficiamento do pescado & 0 \\
Total & 2 \\
Subíndice Econômico (SE) & 0,28 \\
\hline
\end{tabular}

Fonte: Brabo et al. (2015), adaptado pelo autor.

Quanto aos insumos básicos, ração e formas jovens utilizados na produção, foram todos adquiridos localmente, porém com relatos de má qualidade, alta mortalidade e baixo desempenho dos alevinos, além do alto custo da ração, uma vez que, está vem de estados vizinhos, pois o Tocantins não possui fábrica de ração para peixes.

O Parque Aquícola Sucupira e seus cessionários não contam com assistência técnica de forma sistemática e continuada, nem por órgãos governamentais e nem privados. Poucos cessionários tiveram acesso a crédito, a grande maioria aponta a falta de garantias reais como entrave a tomada de crédito, os que obtiveram êxito foi apenas microcrédito para operações de custeio, obtidos de agentes de fomento regionais (Banco do Povo).

O acesso por via terrestre ao empreendimento ficava comprometido no período chuvoso e as estruturas de apoio à produção foram improvisadas. Além de não haver estrutura para beneficiamento do pescado que possibilitasse agregação de valor e diversificação do produto ofertado.

De acordo com a tabela 6 , o subíndice de sustentabilidade econômica encontrado no Parque Aquícola Sucupira foi de 0,28 , classificado como pouco sustentável $(0,26-0,50)$ pela escala de desempenho, de Valenti (2008). Brabo et al. (2015) utilizando-se da mesma escala relataram subíndice de sustentabilidade econômica de 0,14, índice abaixo da classificação mínima para o Parque Aquícola Breu Branco III no reservatório de Tucuruí, estado do Pará. Ambos os empreendimentos se mostraram economicamente insustentáveis, tendo como principais problemas comuns a dificuldade de acesso ao crédito, a ineficiência na gestão da produção e a ausência de estrutura de beneficiamento da produção. 
Mesmo tendo subíndice econômico menor o Parque Aquícola Breu Branco III apresentou vantagem comparativa por possuir assistência técnica disponível aos usuários, fato que não ocorre no Sucupira.

Valenti (2008) relatou que a sustentabilidade econômica de empreendimentos aquícolas perpassa por uma cadeia produtiva organizada e com todos os elos fortes, bem como os ambientes institucional e organizacional.

$\mathrm{Na}$ tabela 7 podemos observar os indicadores de sustentabilidade social, bem como o subíndice social da atividade diagnosticado. Os indicadores referentes à capacitação dos produtores, adaptação dos usuários à atividade e geração de empregos no empreendimento apresentaram condições desfavoráveis à sustentabilidade social do parque aquícola.

Tabela 7. Proposta de indicadores de sustentabilidade para formação do Subíndice Social (SS) preenchida com dados referentes ao Parque Aquícola Sucupira.

\begin{tabular}{lc}
\multicolumn{1}{c}{ Indicador de Sustentabilidade } & Pontuação \\
\hline Conflito pelo uso da água na área do empreendimento & 0 \\
Capacitação dos usuários para atuar na atividade & 0 \\
Atuação da organização social dos usuários & 1 \\
Consumo local da produção & 0 \\
Segurança do empreendimento & 0 \\
Adaptação dos usuários a atividade & 1 \\
Geração de empregos diretos no empreendimento & 0 \\
Total & 2 \\
Subíndice Social (SS) & 0,28 \\
\hline
\end{tabular}

Fonte: Brabo et al. (2015), adaptado pelo autor.

Verificou-se que pela proximidade com a cidade de Palmas e por ser cercado por áreas de lazer, há conflitos pelo uso da água com pescadores artesanais, pescadores esportivos, produtores rurais e outros usuários da área do empreendimento. Não houveram casos de furtos ou depredações das estruturas de criação; porém há vigilância noturna diária dos próprios cessionários.

Quanto a capacitação e treinamento dos usuários, nem todos receberam capacitação para atuar na atividade, o que contraria as condicionantes do licenciamento ambiental de parques aquícolas. A organizações social existente, Associação Bom Peixe, não pratica compras coletivas de insumos, nem tampouco comercializa a produção em conjunto, sendo grande parte da produção consumida localmente.

A grande maioria dos contemplados nos processos de licitação eram pescadores artesanais que nunca tinham praticado piscicultura ou qualquer outra atividade zootécnica em 
sistema intensivo. Não houve contratação de mão de obra fixa em nenhuma das áreas aquícolas do empreendimento.

Mendonça e Valêncio (2008) afirmaram que a eliminação ou deslocamento de pescadores de áreas extrativistas tradicionais e a descaracterização da cultura das comunidades, com a introdução de uma atividade que não faz parte do cotidiano local, são alguns dos impactos sociais negativos que a aquicultura pode promover.

De acordo com a tabela 7, o subíndice de sustentabilidade social encontrado no Parque Aquícola Sucupira foi de 0,28, semelhante ao índice de sustentabilidade econômica, classificado como pouco sustentável $(0,26$ - 0,50) pela escala de desempenho, de Valenti (2008). Brabo et al. (2015) utilizando-se da mesma escala para o Parque Aquícola Breu Branco III no reservatório de Tucuruí, estado do Pará, relataram subíndice de sustentabilidade social de 0,57, classificado como potencialmente sustentável $(0,51-0,75)$ pela escala de desempenho, de Valenti (2008).

A maior contribuição para a sustentabilidade do empreendimento foi dada pelo subíndice ambiental (0,57 - potencialmente sustentável) e houveram uniformidade nos subíndices econômicos e sociais $(0,28$ - pouco sustentável). Sendo assim, o Índice de Sustentabilidade (ISUS) gerado para o Parque Aquícola Sucupira foi de 0,37, classificado como pouco sustentável, comprometendo a previsão de cenários futuros favoráveis, caso ações de estruturação e governança não sejam tomadas.

De acordo com Vilpoux (1997) existem seis modos de coordenação (estrutura de governança) que serão analisados e discutidos neste trabalho de acordo com os dados obtidos na pesquisa com os agentes desta cadeia produtiva, são elas:

a) Mercado: trocas sem contratos, entre atores que não mantêm nenhum contato. $O$ mercado não oferece nenhuma garantia aos agentes, se não a ligada ao respeito do consumidor;

b) Mercado com garantias informais: trocas no mercado entre atores que se conhecem e que mantêm contatos regulares na vida corrente, o que permite criar relações privilegiadas de transação;

c) Acordos contratuais com garantias fracas: onde os contratos instaurados podem ser formais ou não, mas todos os casos apresentam fracas garantias, não trazendo os contratos nenhum seguro sobre a realização da transação;

d) Acordos contratuais com garantias médias: neste caso as probabilidades de respeito dos acordos são superiores ao anterior, porém ainda existindo fraqueza das garantias;

e) Acordos contratuais com garantias fortes (quase-integração): industriais e produtores participam juntos na cultura, com uma divisão final do produto, sendo o bom funcionamento derivado do fato de apoiar-se sobre garantias informais fortes;

f) Integração vertical: os sistemas de garantias totais reencontram-se apenas nos sistemas formais, onde a empresa incorpora todo o processo produtivo. 
De forma a organizarmos e analisarmos os dados do estudo das transações do setor, apresentamos e discutimos os resultados em 6 diferentes sessões de acordo com as características dos agentes entrevistados. Porém em todas elas verificou-se a predominância dos acordos informais, essa informalidade leva a constatação da presença das convenções, que se apresentam de formas variadas conforme o tamanho do empreendimento. A implantação das convenções, que é permitida pelas relações sociais entre os indivíduos, nos permite agrupar os modos de coordenação formais e informais de modo que os custos sejam diminuídos e o sistema seja mais bem coordenado.

\section{Órgãos de Classe - Associação Bom Peixe}

Segundo a presidente da associação, os cessionários necessitam fortalecer a cultura da cooperação através de capacitações e orientações técnicas e gerenciais, bem como clamam por uma governança associativa. Pela carência de ações associativas e ou cooperativistas os produtores são onerados na compra de insumos e na comercialização da produção, tendo resultados econômicos negativos, uma vez que, o custo de produção é muito alto e o valor de venda de seus produtos é baixo. Na grande maioria das transações comerciais ocorrem contratos informais.

A ausência de cooperação e de ações conjuntas, bem como de economia de escala enfraquece o relacionamento com fornecedores e clientes. Segundo Schmitz (1998), a cooperação entre os diferentes atores não representa renúncia da excelência individual e havendo sinergia no sistema interempresarial, há aumento do desempenho individual dos participantes da cooperação. De acordo com Porter (2009), quando a confiança é solidificada nas empresas, os mecanismos elevados dos custos econômicos são diminuídos grandemente, quando amenizados pelas compras em conjunto no interior da aglomeração. Assim como retorno sobre o investimento e maximização dos recursos escassos.

\section{Produtor de alevinos}

O produtor de alevinos tem como produto transacionado principal o peixe in natura (alevinos) e o comercializa diretamente com o produtor que realiza a recria e engorda para comercialização e abate. O preço é sempre imposto pelo produtor de alevinos, sendo esse o agente coordenador da transação, e depende do mercado e dos insumos utilizados na criação. Normalmente os contratos de negócios são informais, uma vez que, os produtores adquirentes são de pequeno porte e as quantidades e valores envolvidos são relativamente baixos. Segundo o entrevistado o fato de não existir contrato formal deve-se a relação de convivência que existe entre os agentes.

A qualidade do produto foi o atributo mais destacado quando perguntado qual a base da 
transação, ou seja, a qualidade pode tanto fortalecer o processo de compra e venda como fazêlos desistir da transação.

Uma demanda percebida pelo setor de produção e solicitada pelos piscicultores foi a produção de alevinos de outras espécies, já que existem diferentes tipos de peixes na região. Segundo Gandra (2010), são estimadas cerca de 1.500 a 2.000 espécies, sendo que 400 são de peixes ornamentais e 100 espécies exploradas para consumo humano. E das 100 para consumo humano, se concentra $85 \%$ na produção em apenas 10 tipos de peixes.

A governança neste setor se dá via mercado, onde o preço e a procura regulam o interesse na produção de alevinos e não há uma coordenação técnica dessas demandas.

\section{Cessionários do Parque Aquícola Sucupira}

Quando estudamos o cessionário piscicultor, o produto transacionado é o peixe, que foi adquirido como alevino, recriado e engordado até o ponto de venda. O preço é imposto pelo consumidor final e pelo mercado concorrente uma vez que os produtores do Parque Aquícola Sucupira não realizam transações comerciais com frigorífico. Mais uma vez estabelece-se a governança via mercado que aumenta os riscos e as incertezas da atividade ao invés da governança técnica.

Como base na transação também foi citada a qualidade e o frescor do peixe (às vezes comercializado vivo) como fator preponderante no processo de compra e venda. Os contratos formais de compra não são utilizados, produtores de pequeno porte não utilizam contrato, sendo as vendas realizadas por telefone, encomendas e no próprio local de produção na maioria dos casos.

A pesquisa demonstrou que muitos atuam na informalidade, e isso pode ocasionar, falta de qualidade nos processos e produtos produzidos ofertados a população.

$\mathrm{Na}$ visão dos produtores, quanto as pesquisas e políticas públicas; falta ouvir o produtor para resolver problemas em conjunto com as instituições. Segundo Porter (2009), só acontecerá aceleração na produtividade se houver interação e transferência tecnológica e gerencial mais profícua com as instituições de ensino e pesquisa. Isso acelera as inovações e aumenta a eficiência produtiva. Observa-se na região, que ainda existe uma relativa desarticulação das Instituições de Pesquisa com o entorno produtivo no que se refere à transferência de inovação tecnológica.

\section{Instituições de Pesquisa, Extensão Rural e Capacitação Empreendedora}

$\mathrm{Na}$ opinião dos produtores a pesquisa de forma geral é mal divulgada e não chega ao campo para transferência de tecnologias que melhorem o sistema produtivo e a extensão rural é descontinua, ineficaz e por vezes mal capacitada, não contando com infraestrutura para atender 
as demandas necessárias. Ainda falta ouvir o público alvo, o produtor, para resolver problemas em conjunto com as instituições.

De acordo com a opinião dos pesquisadores, técnicos e extensionistas ainda existe uma relativa desarticulação das instituições e seu entorno produtivo no que se refere à inovação tecnológica.

Na pesquisa também foi citado por alguns agentes da cadeia produtiva a necessidade de maior participação do SEBRAE - Serviço Brasileiro de Apoio à Micro e Pequena Empresa, na capacitação gerencial, o que é uma lacuna que deverá ser incrementada, pois este órgão tem feito parcerias muito profícuas com o Ministério da Pesca e Aquicultura e está atuando em diversos estados no que concerne à capacitação mercadológica e empreendedorismo.

Segundo Tahin (2008), para se configurar um sistema de governança desenvolvido, deve haver treinamento de recursos humanos, informação, cooperação e conexões com instituições públicas e privadas para fomentar a comercialização com mais produtividade.

As relações contratuais em todos esses casos costumam ser informais, sem contratos e ou garantias de prestação de serviços e ou resultados.

\section{Agências de Crédito e Fomento}

Quanto ao crédito para financiamento, investimento e custeio da atividade, na pesquisa, tanto os produtores quanto os agentes financeiros salientaram que os bancos estatais e particulares, bem como algumas agências de fomento ao microcrédito até apresentam políticas de crédito ao piscicultor, mas sempre atrelado a garantia fundiária e ambiental, além da grande burocracia e da exigência de muitos documentos.

A dificuldade de acesso ao crédito e a falta de comunicação e de ações coordenadas entre as diversas instituições envolvidas no processo, deixa claro a falta de uma governança técnica que alie a capacidade e a viabilidade técnica da tomada de crédito pelos produtores às linhas e programas de crédito oferecidos.

\section{Frigoríficos}

Os produtores do Sucupira nunca realizaram comercialização com frigorífico, seja pela falta de escala na produção, como pela desuniformidade dos peixes ou pela distância e falta de infraestrutura e logística adequada para entrega de seu produto. O produto comercializado é o peixe in natura, no próprio local de produção, sob encomendas ou em comércios locais, porém tudo na informalidade.

A governança é feita via mercado, sem contratos formais e o preço é ditado pela lei da oferta e procura. O custo de produção por vezes tem sido maior que o preço do peixe praticado nos grandes mercados e vindos de outros estados. 
O gerente de frigorífico ouvido na pesquisa relatou que são importantes as questões referentes a legalidade e a sustentabilidade na avaliação de possíveis parceiros comerciais. Segundo o mesmo, observa-se no setor que muitos pequenos produtores repassam sua produção à uma empresa de maior porte em virtude de não possuírem certificação e licenças dos órgãos competentes. Esta, por sua vez, repassa aos produtores um valor muito aquém do investimento na produção, não gerando uma rentabilidade a quem de fato está no processo produtivo.

De acordo com Amato (2009), a atuação de uma governança sólida e de consórcios na região do aglomerado seria uma das viabilidades para atenuar essa questão.

\section{CONSIDERAÇÕES FINAIS}

Os indicadores de sustentabilidade propostos, se mostraram simples e de fácil aplicação e devem balizar o planejamento das fases de implantação e operação dos empreendimentos aquícolas, bem como fornecer subsídios para seu gerenciamento, reduzindo os possíveis impactos negativos da aquicultura, assegurando os aspectos positivos do desenvolvimento social, econômico e ambiental.

Com a determinação dos indicadores de sustentabilidade e de seus subíndices ambiental, social e econômico espera-se desenvolver medidas de mitigação e maximização do Parque Aquícola Sucupira, aproveitando o potencial social e produtivo, garantindo a manutenção da qualidade ambiental e facilitando a interação entre os produtores e os demais órgãos reguladores.

As menores contribuições das dimensões econômicas e sociais identificadas no estudo retratam a desestruturação da cadeia produtiva da piscicultura no estado do Tocantins, bem como a falta de governança e de entendimento entre os diversos atores desta cadeia produtiva.

A ausência de governança para o desenvolvimento e sustentabilidade da produção no Parque Aquícola Sucupira é muito marcante e percebe-se isso em quase todos os seguimentos analisados.

A governança deve influenciar decisivamente no desenvolvimento no arranjo local, pois articula empresas, instituições, e diversos seguimentos para incrementarem a produção e atuarem mais eficazmente nos gargalos na produção.

\section{REFERÊNCIAS}

Amato, N. J. Gestão de Sistemas Locais de Produção e Inovação. (Clusters/APLs). Conceitos, princípios e aplicações de indicadores e benchmarkings. Análise e discussão de casos. São Paulo: Atlas, 2009.

Boyd, C. E.; Tucker, C.; Mcnevin, A.; Bostick, K.; Clay, J. Indicators of resource use efficiency and environmental performance in fish and crustacean aquaculture. Reviews in Fisheries Science, 15(4), 327-360, 2007. 
Brabo, M. F.; Ferreira, L. A.; Veras, G. C.; Cintra, I. H. A.; Paiva, R. S.; Fujimoto, R. Y. 2015. Proposta de indicadores de sustentabilidade para parques aquícolas continentais: avaliação de um empreendimento na Amazônia. Revista Brasileira de Ciências Agrárias, v. 10, n. 2, p. 315-321.

Brasil, Instituto Brasileiro do Meio Ambiente e dos Recursos Naturais Renováveis/IBAMA. 1998. Estabelecimento de normas para a introdução, reintrodução e transferência de peixes, crustáceos, moluscos, e macrófitas aquáticas para fins de aquicultura, excluindo- se as espécies animais ornamentais. Portaria IBAMA n. 145, de 29 de outubro de 1998. Diário Oficial da União, Brasília, 30 out. 1998, Seção1, p.2856.

Brasil, Interministerial. 2004. Estabelecimento de normas complementares para a autorização de uso dos espaços físicos em corpos d'água de domínio da União para fins de aquicultura, e dá outras providências. Instrução Normativa Interministerial n. 6, de 31 de maio de 2004. Diário Oficial da União Brasília, 01 jun. 2004.

Brasil, Ministério do Meio Ambiente, dos Recursos Hídricos e da Amazônia Legal. 1997. Diretrizes Ambientais para o Setor Pesqueiro. Diagnóstico e Diretrizes para a Aquicultura. Brasília, Ministério do Meio Ambiente, dos Recursos Hídricos e da Amazônia Legal, p.60.

Brasil. Ministério da Pesca e Aquicultura/MPA. 2015. Planilha de dados do Sistema de Informação das Autorizações de Uso - SINAU. Dados gerados em 19/10/2017, 2015.

Câmara, J. B. D. Governança Ambiental no Brasil: Ecos do passado. Revista de Sociologia e Política, 21(46), 125-146, 2013.

Carvalho, P. G. M.; Barcellos, F. C. Políticas públicas e sustentabilidade ambiental: construindo indicadores de sustentabilidade. Indicadores econômicos, 37(1), 1-14, 2009.

Cavalcanti, C. Economia e ecologia: problemas da governança ambiental no Brasil. Revibec: Revista Iberoamericana de Economía Ecológica, 1, 1-10, 2004.

Dias, J. D.; Simões, N. R.; Bonecker, C. C. Net cages in fish farming: a scientometric analysis. Acta Limnologica Brasiliensia, 24(1), 12-17, 2012.

Gandra, L. A. O Mercado de Pescado da Região Metropolitana de Manaus. Proyecto Mejoramiento Del Acesso a los Mercados de Productos Pesqueros y Acuícolas de La Amazonia. CFC/FAO/INFOPESCA, 2010.

Humprey, J.; Schmitz, H. Governance and upgrading: linking industrial cluster and global value chain research. IDS Working Paper. Brighton: Institute of Development Studies, University of Sussex JARILLO, C. J. Strategic Networks: Creating. 120, 1-37, 2000

Lakatos, E. M.; Marconi, M. A. Fundamentos de metodologia científica. São Paulo: Revista Atlas, 1991.

Mendonça, S. A. T.; Valêncio, N. F. L. S. O papel da modernidade no rompimento da tradição: as políticas da SEAP como dissolução do modo de vida da pesca artesanal. Boletim do Instituto de Pesca, 34(1), 107-116, 2008.

MPA, Ministério da Pesca e Aquicultura. 2015. Cessão de áreas em parques aquícolas. Acesso em 12/06/2018 às 14:54h. Disponível em: http://www.mpa.gov.br/aquicultura/aguas-dauniao/parques-aquicolas/cessao-de-areas. Acesso em: 12 de jun. 2015.

Porter, M. E. Competição/ On Competition. Tradução Afonso da Cunha Serra. ed. Rev. Amp. Rio de Janeiro. Elsevier, 2009.

Schmitz, H. Eficiência Coletiva: caminho de crescimento para a indústria de pequeno porte. 
Revista Ensaios FEE. 18(2), 164-200, 1998.

Seide, M. F. Proposta de gerenciamento ambiental de parques aquícolas continentais, baseado nos impactos da piscicultura em tanque-rede. 54 pg. Curitiba-PR, 2011.

Silva, A. W. L.; Selig, P. M.; Morales, A. B. T. Indicadores de sustentabilidade em processos de avaliação ambiental estratégica. Ambiente \& Sociedade, 15(3), 75-96, 2012.

Suzigan, W.; Garcia, R.; Furtado, J. Estruturas de governança em arranjos ou sistemas locais de produção. Revista Gestão e Produção. São Carlos, 2007.

Tahin, E. F. Inovação e meio ambiente: o desafio de arranjos produtivos locais de cultivo de camarão em cativeiro no Estado do Ceará. Tese de doutorado da Universidade Federal do Rio de janeiro UFRJ, Instituto de Economia, 2008.

Tiago, G. G. 2007. Aquicultura, Meio Ambiente e Legislação - Segunda Edição Atualizada - 2007 (EBook). São Paulo: Ed. Glaucio Gonçalves Tiago, p.201.

Tiago, G. G. Aquicultura, Meio Ambiente e Legislação. São Paulo: Editora Annablume, p.162, 2002.

Tiago, G. G. Perspectivas Estruturais do Desenvolvimento Sustentável do Agronegócio da Aquicultura Brasileira. Baseado no E-Book: Governança e Sustentabilidade Ambiental: A Aquicultura na Região Metropolitana de São Paulo. ISBN, p. 978-85, 2011

Tiago, G. G.; Cipolli, M. N. Análise Interdisciplinar da Governança Ambiental da Aquicultura na Região Metropolitana de São Paulo. Boletim do Instituto de Pesca, 36, 123-133, 2010.

Valenti, W. C.; Kimpara, J. M.; Preto, B. L. Measuring aquaculture sustainability. World Aquaculture Society Magazine, 43(3), 26-29, 2011.

Valenti, W. C. A aquicultura brasileira é sustentável? Revista Aquicultura e Pesca, 34(4), 36-44, 2008.

Vilpoux, O. Coordinations verticales entre entreprises transformatrices de manioc et producteurs agricoles, au sud du Bresil. Tese (Doutorado). Institute National Polytechnique de Lorraine, p.233, 1997. 